\title{
Analysis of Geo-referenced Building Data for the Identification and Evaluation of Thermal Microgrids
}

\author{
Arno Schlueter ${ }^{1}$, Philipp Geyer ${ }^{2}$, Sasha Cisar $^{3}$ \\ ${ }^{1}$ Architecture and Building Systems, Institute of Technology in Architecture (ITA), ETH Zürich \\ ${ }^{2}$ Archtectural Engineering Division, Department of Architecture, Faculty of Engineering Science, KU Leuven \\ ${ }^{3}$ Chair of Sustainable Construction, Institute of Construction and Infrastructure Management, ETH Zürich
}

\begin{abstract}
Retrofitting the existing building stock is among the most important objectives and imperative to meet societal goals to reduce primary energy demand and anthropogenic greenhouse gas emissions. District heating systems have proven to supply heat for buildings both energy- and cost-efficiently. Thermal microgrids can be understood as a subcategory of district heating systems: small scale, bi-directional, low temperature and potentially fed by different thermal sources. Given a suitable combination of loads, number of and distance between buildings they can offer economic and environmental advantages compared to the supply by individual heating systems per building. We present a novel method using data analysis techniques on geo-referenced building stock data to identify suitable configurations of buildings that yield a cost-efficient thermal microgrid. For the identification both semantic and spatial data from a database are combined using fuzzy logics and cost-benefit analysis. We apply the method using a case study featuring a database of 306 buildings potentially to be retrofitted. As a result, we can identify 9 groups of in total 25 buildings that would form a microgrid featuring up to $17.4 \%$ cost benefits compared to an individual heat supply. This would save approximately $30 \%$ of the building induced $\mathrm{CO}_{2}$ emission of the community.
\end{abstract}

Keywords: building retrofit, district heating, thermal microgrids, clustering, fuzzy logics, GIS, costbenefit analysis

\section{Introduction}

In Europe, retrofitting of the existing building stock is one of the most important objectives and imperative to reduce anthropogenic greenhouse gas emissions (GHG). In temperate climates, most of the building-induced GHG are emitted by the heating systems that are mostly still based on fossil fuels. In Switzerland, for example, $70 \%$ of the residential buildings use oil or gas heating [1]. Current retrofit rates however range only between $1-2 \%$, therefore necessary upgrade of the building stock only happens slowly.

District heating systems have proven to be an efficient and cost-effective alternative to individual heating systems. Conventional district heating systems are mostly large scale, aiming at many connected buildings with large heating loads. It usually consists of one-to-many connections from a central heating plant to the consumer using a distribution network. Due to decreasing loads of low-energy buildings, the competitiveness of conventional district heating systems is under pressure [2].

Thermal microgrids (TMG) can be understood as small scale thermal networks that connect multiple and decentralized heat sources, storage and consumers. As buildings increasingly utilize local renewable energy sources such as geothermal or solar thermal energy, connecting them offers benefits

\footnotetext{
${ }^{1}$ Corresponding author: Arno Schlueter, Professorship of Architecture and Building Systems, John-von-Neumann Weg 9, 8093 Zürich, Switzerland; email: schlueter@arch.ethz.ch
} 
for exchanging heat between producers and consumers and thus balancing demand and supply of stochastic sources and consumption. Addressing not only energy but also exergy efficiency, such networks can be operated at much lower temperatures than conventional district heating systems. The concept of thermal microgrids is especially interesting for small-scale local networks, for example among neighbors. Short distribution distances, a reduction of investment costs due to economies of scale, joint investment capacities and local balancing of demand and supply are some of the benefits that make TMG attractive. The challenge for leveraging these benefits is, however, to identify suitable building candidates within the building stock. Due to the exponential growth of possible combinations, manual search for combinations within large building stocks is next to impossible. New methods and tools that utilize geographical information systems and energy systems analysis are necessary to identify optimal configurations of heat production and choice of technologies [3].

In this work we propose a two-step method to identify suitable configurations of buildings within a large building stock for which a thermal microgrid yields cost-efficiency benefits and thus supports the mitigation of GHG. First, buildings need to be identified for which the exchange of the current heating system would be beneficial, which represents a filtering problem. Second, as thermal energy networks are dependent on the spatial distribution of nodes, the spatial relation of the building candidates needs to be considered.

The paper is structured as follows. In section 2 we provide the relevant background on district heating, thermal microgrids, the use of information systems and related data analysis techniques with special focus on applications for the built environment. In section 3 we describe the method for automated identification of microgrid candidates and cost-efficiency evaluation before we apply it on a case study using building data of 306 buildings in section 4. In section 5 we discuss the results and provide an outlook on further steps.

\section{Background}

\subsection{District heating systems (DHS)}

\subsubsection{Benefits and challenges}

Extensive research and application have proven the economic and environmental viability and benefit of district heating systems (DHS), also for low-energy building applications. Olsen et. al [4] mention the flexibility and direct integration of Renewable Energy Sources (RES) in combination with largescale heat sources as advantages of a low-energy DHS. They demonstrate that over a 30-year period, a low-energy district heating systems can be competitive and offers economic advantages compared to individual ground-source or air-source heat pump solutions. Dalla Rosa and Christensen [5] use a case study to show that a low temperature district heating for low-energy housing can be realized at approximately $20 \%$ lower cost for the energy unit than a scenario based on individual ground source heat pumps. On a larger scale, Lund et al., [6] examine the future role of DHS in Denmark using 100\% RES and reducing the space heating demand by $75 \%$, showing that by consequent application it can make a substantial contribution to the reduction of fossil fuels and thus $\mathrm{CO}_{2}$ emissions. 
Recent studies have also looked into small scale and scarce density district heating systems. Truong and Gustavsson [7] investigate a small scale district heating system in respect to various generation technologies and conclude that the smaller the heat production the lesser the benefit of co-generation of heat and electricity is. Reidhav and Werner [8] conducted a large study on over 3000 single family houses in Sweden and demonstrate that the economic profitability of such sparse district heating is strongly connected to the distribution costs, marginal costs for heat generation and non-technical factors such as polices and taxation. They conclude that district heating in sparse areas can be profitable but, in the Swedish context, requires an annual heat delivered per house of $50 \mathrm{GJ} / \mathrm{a}$ and a linear heat density greater than $2 \mathrm{GJ} / \mathrm{m}$ or more.

The general challenge of a thermal network is the distribution of heat, the related heat losses and pumping costs. For an economically competitive solution, generation and distribution costs must not be higher than for an individual solution, therefore the distribution costs must be lower than the difference between individual and district heat generation costs [2], [9]. This accounts for both, energy as well as monetary costs. Key parameters influencing the efficiency of distribution are heat losses, pumping costs and load management. Heat losses are greatly influenced by the chosen system temperatures, flow rates, pipe properties and length. In conventional systems they account for up to 5-15\% of the heat delivery [9]. Current and future low-energy buildings are especially challenging as the require much less heat. Pumping costs in electricity are influenced by the pressure drop in the network, necessary flow rates and pipe properties. However, they only account for approximately $0.5 \%$ of the heat delivery [9].

\subsubsection{Geographical information systems for energy systems design}

Due to advances in Geo-Information Systems (GIS) and available computing power, spatial methods are increasingly utilized for analyzing and designing large scale energy systems. The work of [10] provides an overview on the research on GIS in the field of renewable energy sources, distinguishing between three core research fields, a) decision support systems, b) the evaluation of distributed electricity generation and c) decentralized generation and rural electrification. Cities such as London have mapped heat demand and existing networks [11] in order to identify potential areas for future DHS. Nielsen and Möller [12] describe the relation between placement of buildings and the potential for the application of DHS. Ideal configurations show both, a large demand within a confined area and the availability of local heat sources. They utilize a GIS model containing all necessary information for cost evaluation in order to identify suitable areas for DHS in Denmark from a socio-economic perspective. Besides the mapping of information such as the heat demand, GIS databases are used for spatial analysis related to RES potential analysis, development and deployment.

\subsubsection{Thermal microgrids}

Thermal microgrids (TMG) can be understood as a sub-category of district heating. They are characterized by small spatial dimensions in which they connect different decentralized consumers, producers and storage facilities. An exemplary TMG, for example, might connect a building with solar thermal generation, a building that supplies waste heat, a geothermal storage with a central or several 
decentralized heat pumps to achieve different levels of temperatures required for the different uses in the buildings connected. Another characteristic of TMG is that they ideally supply buildings that use low-temperature space heating systems which require low inlet temperatures just above room temperature. This also impacts the temperatures of heat to be supplied and thus the operational temperature of the TMG. Following the principle of low-exergy, temperature differences between the heat source and the application are kept as low as possible by optimally matching demand and supply [13], [14]. High efficiency, low-lift heat pumps can be used to generate the necessary heat using only a fraction of high potential energy such as electricity (exergy) and environmental heat (anergy) to generate the necessary heat [15]. This fraction is expressed by the Coefficient of Performance (COP). Current implementations show a COP above 4 [16] and higher up to 13 in lab settings [15], which means that a heat pump uses 1 unit of exergy, in this case electricity, to deliver 13 units of heat to the building. This allows for the efficient use of environmental heat sources such as ground heat and low temperature waste heat for heating applications. Whereas district heating systems of the current $3^{\text {rd }}$ generation use operational temperatures below $100^{\circ} \mathrm{C}$ [3], low temperature district heating systems operate at temperatures between 10 and $20^{\circ} \mathrm{C}$ when using decentralized heat pumps [17] and around approximately 35 to $40^{\circ} \mathrm{C}$ when using a centralized heat pump. Lower supply temperatures also result in significantly lower distribution heat losses and the option of utilizing seasonal storage using ground heat exchangers. Studies and first installations on district scale in Switzerland show the potential to attain significant performance and thus reductions of $\mathrm{CO}_{2}$ for building operation [16], [18].

\subsection{Methods of data analysis: filtering and clustering}

To identify suitable building candidates to form thermal microgrids, first a filtering problem and second a problem of spatial proximity needs to be solved. Fuzzy logic and clustering represent suitable methods to address these problems.

\subsubsection{Fuzzy logic}

For filtering problems combining multiple criteria, fuzzy logic represents an intuitive-to-use and widespread method used in typical engineering applications. Harris, Sivanandam et. al and Suganthi et. al [19]-[21] provide overviews of fuzzy logic application related to renewable energy. Most applications however do not have a direct spatial relation. Typical examples apply fuzzy functions to spatial data fields or field-like characteristics often represented in GIS [22]-[24]. Furthermore, Dutta [25] manages spatial constraints on a set of landmarks by means of fuzzy logic applied to derived features. Chow and Tram [26] and Ying and Pan [27] use fuzzy logic for load forecasting of land use and assess derived spatial characteristics such as distance from a highway using fuzzy logic. Arabacioglu [28] uses fuzzy functions to assess spatial properties of architectural space. However, there are no applications of fuzzy logic that use the proximity of objects and thus spatialize a fuzzy logic as it is required for the intended microgrid identification.

\subsubsection{Hierarchical and partitioning clustering}

Clustering is a widespread method to classify data into groups or clusters. Xu and Wunsch [29] describe foundations and current state-of-the-art of the method. The combination of network design 
and clustering as a data analysis technique is used for different applications in context to infrastructure such as to detect and map water pollution [30], to profile road accident hotspots [31] or to identify local wind patterns for the modelling of renewable energy systems [32]. Fazlollahi et. al [33] utilize GIS data and clustering of urban areas for optimizing the design and operation of district energy systems, identifying zones 'where consumers, resources and technologies are integrated'. Cartina et al. [34] apply clustering to electrical networks to identify feeder characteristics. Further cases in building stock management are discussed in the next subsection.

"As clustering relies on the distance between objects, it is inherently spatial." [35]. Therefore, clustering is appropriate for the identification of spatial relation of objects but not for the filtering by qualitative criteria. However, as buildings stocks to be analysed may be large, efficient spatial clustering is of interest. There are two main classes of clustering methods: hierarchical clustering and partitioning clustering. Whereas hierarchical clustering has a typical computational complexity of $O\left(N^{2}\right)$, the partitioning clustering algorithm k-means performs better with a complexity of $O(N K d)$ with $N$ objects, $K$ clusters and $d$ dimensions [36]. However, k-means assumes a fixed number of clusters and convex cluster sets. For purpose of comparison, these two types serve as representative clustering algorithms in the paper.

\subsection{Building stock management}

\subsubsection{Building stock models and retrofit strategies}

For predicting the future energy use with related emissions and for evaluating scenarios and strategies, building stock models are important. Swan and Ugursal [37] and Kavgic et al. [38] review the state of the art techniques of building stock modelling in research, the existing models and approaches and their use for policy making. The typical parameters that these models build on are categories of building age, type of building, heat distribution type, energy source, construction or year of refurbishment and type of dwelling. Bottom-up building engineering models serve to assess the reduction potentials of energy efficiency measures and technologies for the building stock based on these parameters. For this purpose, the approaches usually define scenarios that apply measures over the entire building stock following standard combinations of measures and performance estimation. However, these models are usually suited for analysis only and do not derive solutions and planning strategies, such as the proposal of microgrid configurations. Furthermore, different classification methods are applied to buildings stock data. Usually, the parameters in the building stock data are used to derive groups and to assign measures for energy efficiency. A typical example is the type-age classification that has been developed for Germany by the Institut für Wohnen und Umwelt [39] and recently extended to Europe.

\subsubsection{Clustering and buildings stocks}

In terms of more sophisticated data analysis techniques different approaches related to energy use in building stocks exist. Santamouris et. al [40] apply clustering to a database of 320 schools in Greece and build groups based on normalized energy consumption. Gaintani et al. [41] identify typical building properties and parameters of the schools using k-means clustering. Jones et. al [42] cluster a building stock by building properties, such as heated ground floor area, facade, window to wall ratio. 
Yamaguchi et.al [43] identify district types and provide typical energy performance by simulating buildings in a representative district. However, all these classification approaches mostly focus on energy demand and retrofit actions and use either building parameters, such as age or usage, or the energy consumption for classification. None of them considers the suitability of buildings for microgrids as a classification category.

Moreover, as part of the research project 'Zernez Energia 2020' [44] which also serves as the case study for this work, the authors have recently developed a method to cluster buildings based on the performance of retrofit measures [45]. The method allows identifying groups of buildings that react similar to retrofit measures. By identifying groups of buildings and their most cost-efficient retrofit measures, the development of retrofit strategies for the entire building stock is possible and has been executed as part of the project.

However, the application of retrofit measures as developed in the aforementioned approach does not utilize the available spatial data. Thermal microgrids strongly rely on spatial considerations; their performance depends on the number and distance of buildings included. Due to the many different possible combinations of connections between buildings the extension of the performance-based clustering method for the identification of thermal microgrids would cause high computational loads. For this reason we utilize fuzzy logics as presented in the following section.

\section{Multi-dimensional data analysis for thermal microgrids}

\subsection{Thermal microgrid design}

The thermal microgrid setup in this approach is based on borehole ground heat exchanges (GHE) for ground heat extraction and seasonal heat storage. A central heat pump creates the required temperature for low temperature heating applications such as thermally activated slabs, floor-, ceiling- or wall heating. The heat is distributed using an underground water network operated at low temperatures. The small temperature difference between the supply and the environment temperature allows for small distribution heat losses. The small temperature difference between the source and the heating inlet temperature allows for a high coefficient of performance (COP) of the heat pump, thus requiring low electricity consumption for heat generation. Due to reasons of heating capacity, efficiency and comfort a low temperature heating system is only feasible given an appropriate insulation of the envelope.

\subsection{Building candidate selection criteria}

The GIS building database is used as data source for both spatial and building data. In terms of building data, the $\mathrm{CO}_{2}$ emissions and the age of the current heating systems are the first decisive parameters. $\mathrm{CO}_{2}$ conversion factors in combination with data on heating end-use demands and type of the heating system are used to estimate $\mathrm{CO}_{2}$ emissions. If the current heating system emits large amounts of $\mathrm{CO}_{2}$ or the heating system of the building is older than 20 years, the building is selected as potential candidate. If a heating system is older than 20 years it has or will soon reach end of life, its retrofit is therefore upcoming and thus the opportunity to change to a heating system with less emissions. The spatial data used for the clustering are the geo-coordinates of the buildings. 


\subsection{Microgrid identification and evaluation}

As in large building stocks the identification of suitable groups is a difficult task, the central objective of the evaluation and performance assessment procedure is the automated identification of building groups for potential microgrids. The basis for this process is the translation of the selection criteria to fuzzy evaluation functions that are applicable to the building stock database. Then fuzzy logic identifies buildings that are close enough to each other and fulfil the other criteria.

Instead of considering the real pipe length for the identification process we use a simplified proximity criterion based on the distance between the selected buildings which is generated automatically using the coordinates of the buildings. The objective is to avoid the laborious layout of networks that is not possible for the combinations of all possible network configurations. For the 306 buildings in the test building stock of Zernez, $2^{306}$ combinations are possible, which is approximately $1.3 \cdot 10^{92}$. The limitation of the size of microgrids for example to a maximum of five buildings per network reduces that number to $2.1 \cdot 10^{10}$, which is still very high. Therefore, due to the many possible combinations, even when using automated approximations for the pipe length, the calculation of pipe length and performance would lead to a very high computational load even for the small building stock of the case study. For this reason, the identification process is based on a pair-wise comparison involving only two buildings instead of larger groups; this leads to distance matrix with 93'000 members to be calculated, which is more feasible. After the potential microgrid identification more precise methods to estimate the pipe length are used.

\subsubsection{Fuzzy functions}

We use fuzzy functions, as described by [19] to translate the selection criteria into unique mathematically defined and computable functions. For this purpose, one-sided triangular fuzzy functions, as shown in Figure 1, are used to generally define the membership

$$
\mu\left(x, x_{l}, x_{u}\right)= \begin{cases}x<=x_{l} & 0 \\ x>x_{l} \wedge x<x_{u} & \frac{x-x_{l}}{x_{u}-x_{l}}, \\ x>=x_{u} & 1\end{cases}
$$

where $x$ is the value to be assessed and $x_{1}$ and $x_{\mathrm{u}}$ are the lower and upper limit of the ramp.

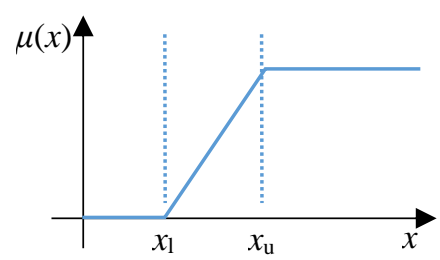

Figure 1: Scheme of the fuzzy function used

This approach allows the assessment of values of one building, e.g., the age of the heating or the building's $\mathrm{CO}_{2}$ emissions. 


\subsubsection{Spatial fuzzy functions}

Whereas these fuzzy functions only deal with building data of a single building, microgrids involve more buildings including their spatial configuration. For this purpose, the evaluation is extended using spatial information in fuzzy functions. As first example, a membership function of closeness of two buildings is set up. This spatial extension of the membership function uses a Euclidian distance function $d$ :

$$
d\left(B_{i}, B_{j}\right)=\min \left(\sqrt{\left(x_{j, m}-x_{i, n}\right)^{2}+\left(y_{j, m}-y_{i, n}\right)^{2}}\right) \text { with indices } m=1 . . m_{\max } ; n=1 . . n_{\max },
$$

where $x$ and $y$ are the corner coordinates with the least distance of two buildings $B_{1}$ and $B_{2}$. An additional algorithm determines the closest corners to use for this purpose. The pairwise comparison for all buildings forms the distance matrix $\mathbf{D}$ that has the size $n^{2}$ for $n$ buildings, which is in case of 306 buildings approximately $93^{\prime} 000$. The application of the membership function $\mu_{\text {is close }}$ on $\mathbf{D}$ identifies all pairs of buildings that are close enough to form a microgrid.

\subsubsection{Criteria translation}

Figure 2 shows the membership functions $\mu_{\text {high emissions }}$ for the emissions, $\mu_{\text {old heating system }}$ for the age of the heating system and $\mu_{i s c l o s e}$ for the distance with a histogram showing the frequency of the parameters in the database of the case.
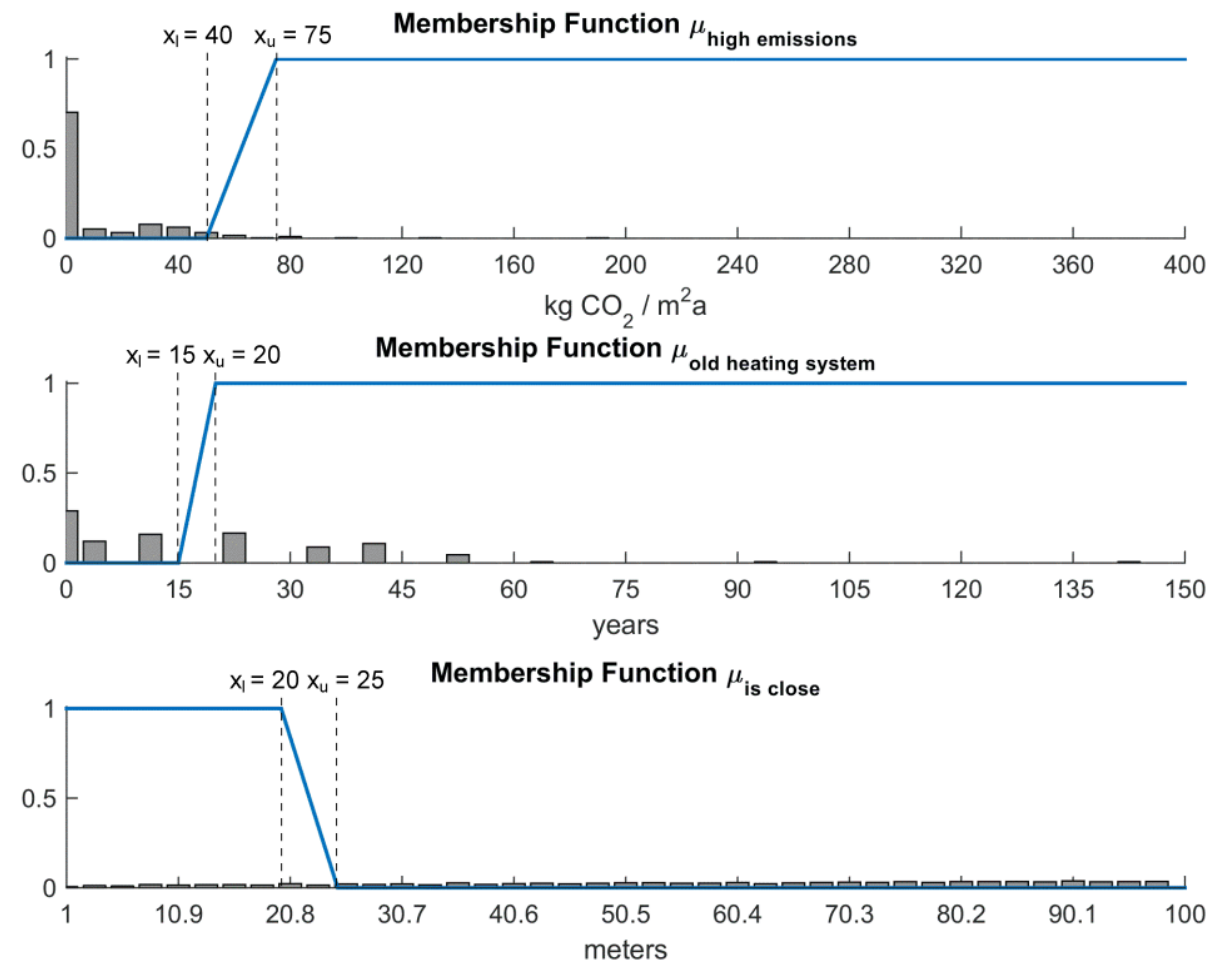

Figure 2: Membership functions for the criteria combined with percentage histograms 


\subsubsection{Identification of microgrids}

After the evaluation of the data by the three membership functions, a fuzzy logic function serves to identify candidates for microgrids. This function identifies building pairs that have high emissions or an old heating system and that are at the same time close enough to form a microgrid. The fuzzy logic function for this purpose is

$$
\mu_{\text {micro grid affine }}=\left(\mu_{\text {much emissions }} \vee \mu_{\text {old heating system }}\right) \wedge \mu_{\text {is close }} \text {. }
$$

The resulting membership function $\mu_{\text {micro grid affine }}$ delivers a microgrid matrix $\mathbf{M}$ with the building pairs suitable for microgrids; the matrix has the same dimensions as the distance matrix but a range from 0 to 1. A further algorithm identifies clusters, which are the proposed microgrids, among this pair matrix by agglomerating connected buildings in the matrix and adds up the distance and the heat demand per cluster; these data allow assessing the performance of the microgrid.

\subsubsection{Alternative identification for large data set}

The complexity of the method described up to here is $O\left(N^{2}\right)$. For large data sets, a more good-natured scaling is of interest. For this purpose, it is possible to replace pair-wise comparison of proximity determination by using well-established clustering algorithms. As a consequence, fuzzy logic is only used to filter for buildings that require a new heating system, neglecting the spatial aspect of proximity:

$$
\mu_{\text {new heating system }}=\mu_{\text {much emissions }} \vee \mu_{\text {old heating system }} \text {. }
$$

In a next step, all building candidates identified by filtering are arranged using clustering algorithm to form the microgrids. Input for this process are the locations of the centers of the buildings with the advantages described above, such as a k-means algorithm with a complexity proportional to $N$.

\subsubsection{Evaluation of microgrids}

The main evaluation criterion is the reduction of $\mathrm{CO}_{2}$ emissions of a retrofit measure in relation to the expected investment cost, which determines the cost-effectiveness of the measure. This concerns the microgrid solution as well as the alternative, in this case the installation of a ground heat exchanger and a heat pump. The investment costs are chosen as they represent the main fraction of the total costs and are the decisive factor for building owners. The cost effectiveness $e$ is defined as:

$$
e=\frac{\Delta V_{C O_{2}}}{\Delta c_{i n v}}
$$

where $\Delta V_{C O 2}$ is the reduction of $\mathrm{CO}_{2}$ emissions in tons per year for the measure and $\Delta c_{i n v}$ its investment costs.

For assessing the emissions, the changes in efficiency of the heat supply system, the conversion factors of the energy sources used and the heat losses caused by the transport in the pipes are considered. The 
effect on emissions $\Delta V_{\mathrm{CO} 2}$ is defined as the difference of the current emissions of the buildings assigned to the cluster $V_{C O 2, e x}$ to the expected emissions of the new microgrid configuration $V_{C O 2, m g}$ :

$$
\Delta V_{\mathrm{CO}_{2}}=V_{\mathrm{CO}_{2}, \mathrm{mg}}-V_{\mathrm{CO}_{2}, e x}
$$

In detail, the sum of the thermal energy demand of the buildings $Q_{t h}$ combined with the respective system effectiveness $\eta$ and the conversion factor $k$ coupled to the used energy source define the emissions:

$$
\begin{gathered}
\Delta V_{\mathrm{CO}_{2}, m g}=\eta_{m g} k_{m g}\left(Q_{l o s s}+\sum Q_{t h, i}\right) \text { and } \\
V_{\mathrm{CO}_{2}, e x}=\sum \eta_{e x, i} k_{m g, i} Q_{t h, i}
\end{gathered}
$$

Data for $\eta$ and $k$ are listed in the Appendix, Table 1.

In case of the microgrid solution, the heat losses of the network $Q_{h l}$ also need to be added to the heat demand. To estimate the heat losses we use the approach by Frederiksen and Werner [9]. The losses depend on the on the pipe length $L$, the average pipe diameter $d_{a}$, the degree hours $G$ and the transmission coefficient $K$ :

$$
Q_{h l}=K 2 \pi d_{a} L G
$$

The degree hours for a low-temperature thermal such as for the case study can be approximated to $500,000^{\circ} \mathrm{Ch}$ [9]. With a transmission coefficient $K$ of $0.25 \mathrm{~W} / \mathrm{m}^{2} \mathrm{~K}$ and an average diameter of $0.025 \mathrm{~m}$, the annual heat losses are $19.6 \mathrm{kWh} / \mathrm{m}$

\subsubsection{Investment Costs}

The data used for the calculation of the investment costs for the heat distribution network $c_{\text {network}}$, the fixed and variable costs for the plant (ground heat exchanger and heat pump) $c_{\text {peak,plant }}$ and $c_{\text {fix } x \text { lant }}$ are based on empirical surveys of actual building costs in Switzerland within the framework of the GEAK [46].

The pipe diameters are approximated using the equation from Frederiksen and Werner [9]. They are derived from existing heating networks and use the linear heat density $\left(Q s / l_{p i p e}\right)$ as a key indicator, where $Q_{s}$ is the heat delivered to the building and $l_{p i p e}$ the length of the pipe route as estimated above:

$$
d_{\text {pipe }}=0.0486 * L N\left(\frac{Q_{S}}{l_{\text {pipe }}}\right)+0.0007
$$

The investment costs for the microgrid solution can be estimated by adding the costs of the distribution network to the fixed and variable costs of the heating plant:

$$
c_{\text {inv }}=\left(c_{\text {network }} * l_{\text {network }}\right)+\left(c_{\text {peak,plant }} * P_{\text {peak }}\right)+c_{\text {fix,plant }}
$$


Using $l_{\text {pipe }}, d_{\text {pipe }}$, and the peak load of the microgrid $P_{\text {peak }}$, the investment cost $c_{i n v}$ for the microgrid in context of the case study used can be estimated:

$$
c_{\text {inv }}=\left(7050 \frac{C H F}{m^{2}} * d_{\text {pipe }}+750 \frac{C H F}{m}\right) * l_{\text {pipe }}+\left(9000 \frac{C H F}{k W} * P_{\text {peak }}+29000 \mathrm{CHF}\right)
$$

To calculate the investment costs for the individual heat supply of a building using a ground heat exchanger and heat pump only the plant costs are used.

\subsubsection{Cost benefit}

The cost benefit of a microgrid solution $\Delta c_{\text {supply }}$ can be calculated by comparing the costs of the microgrid solution with the costs of individual supply solution, taking into account the number of buildings $n_{B}$ to be supplied. As the costs linked to the heating load $P_{\text {peak }}$ are the same for both solutions they cancel out.

$$
\Delta c_{\text {supply }}=\left(c_{\text {network }} * l_{\text {network }}+c_{\text {plant }, M G}\right)-\left(c_{\text {plant }, \text { ind }} * n_{B}\right)
$$

Using the costs for network and generation from above leads to the estimation of cost benefit of a microgrid as a function of the pipe diameter $d_{\text {pipe }}$, the length of network $l_{\text {pipe }}$ and the number of buildings $n_{B}$ to be supplied:

$\Delta c_{\text {supply }}=\left(7050 \frac{C H F}{m 2} * d_{\text {pipe }}+750 \frac{C H F}{m}\right) * l_{\text {pipe }}+29000$ CHF $-\left(29000\right.$ CHF $\left.* n_{B}\right)$

The plant costs exhibit the effect of economies of scale: Using one large plant instead of many small ones distributes the fixed investment costs and thus lowers the costs for the individual building.

\section{Application scenario}

\subsection{Case study}

For the application and exploration of the approach we utilize the research project Zernez Energia 2020 as case study. The aim of the interdisciplinary research project is to develop a roadmap to transform the building stock of the alpine village of Zernez to become free of $\mathrm{CO}_{2}$ emissions in building operation. For this purpose, measures on building level such as retrofit as well as on infrastructural level such as extension of the existing district heating system and new means of heat and electricity generation are researched. As part of the project, detailed information of 306 buildings has been acquired using municipal data as well as own surveys. This data is stored in a geo-referenced (GIS) database with over 50 parameters per building. The database is primarily used for the evaluation and optimization of costoptimal retrofit measures for the building stock in order to obtain a transformation strategy towards zero emission in operation. As part of this analysis, a variety of different retrofit options are simulated, assessed and clustered. The approach and process is described in [45], [47].

Analyzing the surveyed building data reveals first insights, for example related to building age and $\mathrm{CO}_{2}$ emissions: It is not the oldest buildings from the 1870's that have the highest relative emissions but buildings from the 1920's and 2000's, the latter showing the highest total energy consumption per square meter. The same analysis for the year of installation the heating system leads to similar results. 
For the buildings of the case study there is therefore no direct correlation between the age of the building, the age of its heating system and the $\mathrm{CO}_{2}$ emissions. However, as the lifetime of a heating system is limited, it is more likely that older heating systems are exchanged than new ones, proving an opportunity for exchanging with a new heating system that emits less $\mathrm{CO}_{2}$.

\subsubsection{Heating systems setup}

For the reason described above, both the individual heat supply solution and the thermal microgrid use a ground heat exchanger and a heat pump for heat generation. This combination allows for maximum mitigation of $\mathrm{CO}_{2}$, is feasible and applied on community grounds. Furthermore, the remaining electricity for heat generation can be supplied using hydropower which is generated on community grounds, making this a nearly zero emission heat supply. As a prerequisite for an efficient operation of the heat pump, the building envelope needs to be sufficiently insulated. Using the database, the current actual heating energy demand is used, the existing state of the envelope is assessed, additional insulation is applied if necessary and applicable, and the resulting demand is estimated [47]. The heating load $P_{\text {peak }}$ is derived using approximate load hours for alpine regions [48].

\subsection{Results}

\subsubsection{Microgrids identification and evaluation}

Using the method described above, 16 potential microgrids featuring between 2 and 28 building members are identified (Table 1and Figure ). These buildings exhibit high $\mathrm{CO}_{2}$ emissions for heating, their heating system has reached or is near its end of life and they are within a certain vicinity. The total sum of building connected in 16 microgrids is 107 , which means that roughly $1 / 3^{\text {rd }}$ of the buildings of the community show a potential of $\mathrm{CO}_{2}$ savings using a microgrid. The selected buildings are of mixed building typology such as single family houses, multi-story residential and non-residential such as hotels and schools. This is illustrated by the difference in heating load between 13 and 1355 GJ/a (Figure 3). The largest group of buildings however exhibits a heating load between 50 and $150 \mathrm{GJ} / \mathrm{a}$.

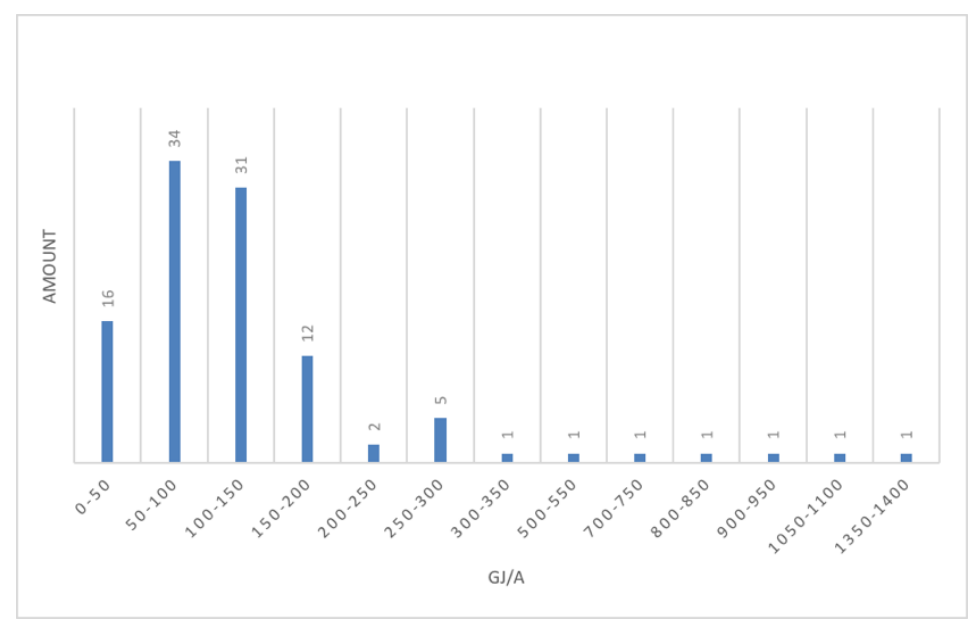

Figure 3: Heating load distribution for all (107) buildings

The distribution networks connecting all identified buildings of a microgrid are routed to target the shortest connecting path by assuming that routes can run through the lots of member buildings. The 
cost benefit of the microgrids identified over the individual solutions are assessed using the calculations described above and displayed in Table 1.

\begin{tabular}{|c|c|c|c|c|c|c|c|c|c|}
\hline $\begin{array}{l}\text { Microgrid } \\
\text { No }\end{array}$ & n Buildings & $\begin{array}{l}\text { Distance } \\
\text { sum [m] }\end{array}$ & $\begin{array}{c}\text { Lenght of } \\
\text { Network [m] }\end{array}$ & $\begin{array}{c}\text { Heating Power } \\
{[\mathrm{kW}]}\end{array}$ & $\begin{array}{c}\text { Reduction } \\
\mathrm{CO} 2 \mathrm{t} / \mathrm{a}\end{array}$ & $\begin{array}{c}\text { Costs MG } \\
\text { [CHF] }\end{array}$ & $\begin{array}{c}\text { Cost } \\
\text { Individual } \\
\text { [CHF] }\end{array}$ & $\begin{array}{c}\text { Cost benefit } \\
\text { [CHF] }\end{array}$ & $\begin{array}{c}\text { Cost } \\
\text { benefit \% }\end{array}$ \\
\hline 1 & 3 & 16 & 17.8 & 12.1 & 24.0 & $161 ' 564$ & $195 ' 605$ & $344^{\prime} 041$ & $17.4 \%$ \\
\hline 5 & 3 & 25 & 31.3 & 9.5 & 77.0 & $148^{\prime} 287$ & $172^{\prime} 745$ & 24 '457 & $14.2 \%$ \\
\hline 13 & 2 & 3 & 3.5 & 15.5 & 30.0 & $175^{\prime} 742$ & $197^{\prime} 778$ & 22 '036 & $11.1 \%$ \\
\hline 16 & 4 & 18 & 24.9 & 51.6 & 206.0 & $536 ' 545$ & $580^{\prime} 563$ & $44^{\prime} 018$ & $7.6 \%$ \\
\hline 10 & 2 & 12 & 15.6 & 11.5 & 14.0 & $153^{\prime} 789$ & 161 '351 & 7'562 & $4.7 \%$ \\
\hline 9 & 2 & 0 & 11.2 & 20.8 & 94.0 & $235 ' 312$ & $245^{\prime} 366$ & 10 '054 & $4.1 \%$ \\
\hline 7 & 5 & 56 & 57.8 & 90.0 & 92.0 & $933^{\prime} 717$ & $955^{\prime} 439$ & $21^{\prime} 722$ & $2.3 \%$ \\
\hline 14 & 2 & 8 & 9.1 & 55.7 & 121.0 & $548 ' 976$ & $558 ' 869$ & 9'893 & $1.8 \%$ \\
\hline 12 & 2 & 15 & 14.2 & 49.9 & 5.0 & $505^{\prime} 231$ & $507^{\prime} 111$ & 1'881 & $0.4 \%$ \\
\hline 15 & 6 & 131 & 107.9 & 105.4 & 14.0 & 1'136'075 & 1'122'346 & $13^{\prime} 729$ & $-1.2 \%$ \\
\hline 3 & 3 & 57 & 42.8 & 163.7 & 262.0 & 1'585'153 & 1'560'172 & 24 '981 & $-1.6 \%$ \\
\hline 4 & 17 & $1^{\prime} 013$ & 344.4 & 304.7 & 4.0 & 3'262'024 & 3'206'676 & $55^{\prime} 348$ & $-1.7 \%$ \\
\hline 2 & 7 & 201 & 174.4 & 81.0 & 47.0 & $970 ' 086$ & 931'944 & $38 ' 142$ & $-4.1 \%$ \\
\hline 8 & 15 & 983 & 454.9 & 171.8 & 118.0 & 2'096'446 & 1'981'338 & \begin{tabular}{|l|}
$-115^{\prime} 108$ \\
\end{tabular} & $-5.8 \%$ \\
\hline 11 & 28 & 3'412 & 1035.9 & 556.3 & 101.0 & 6'346'993 & 5'818'378 & $-528^{\prime} 615$ & $-9.1 \%$ \\
\hline 6 & 5 & 125 & 168.3 & 73.0 & 76.0 & $887^{\prime} 192$ & $802^{\prime} 368$ & 84 '824 & $-10.6 \%$ \\
\hline
\end{tabular}

Table 1: Microgrid identified for the building stock of the case study, properties and cost benefit

The microgrids, their member buildings, their location and distribution over the village is shown in Figure 4.

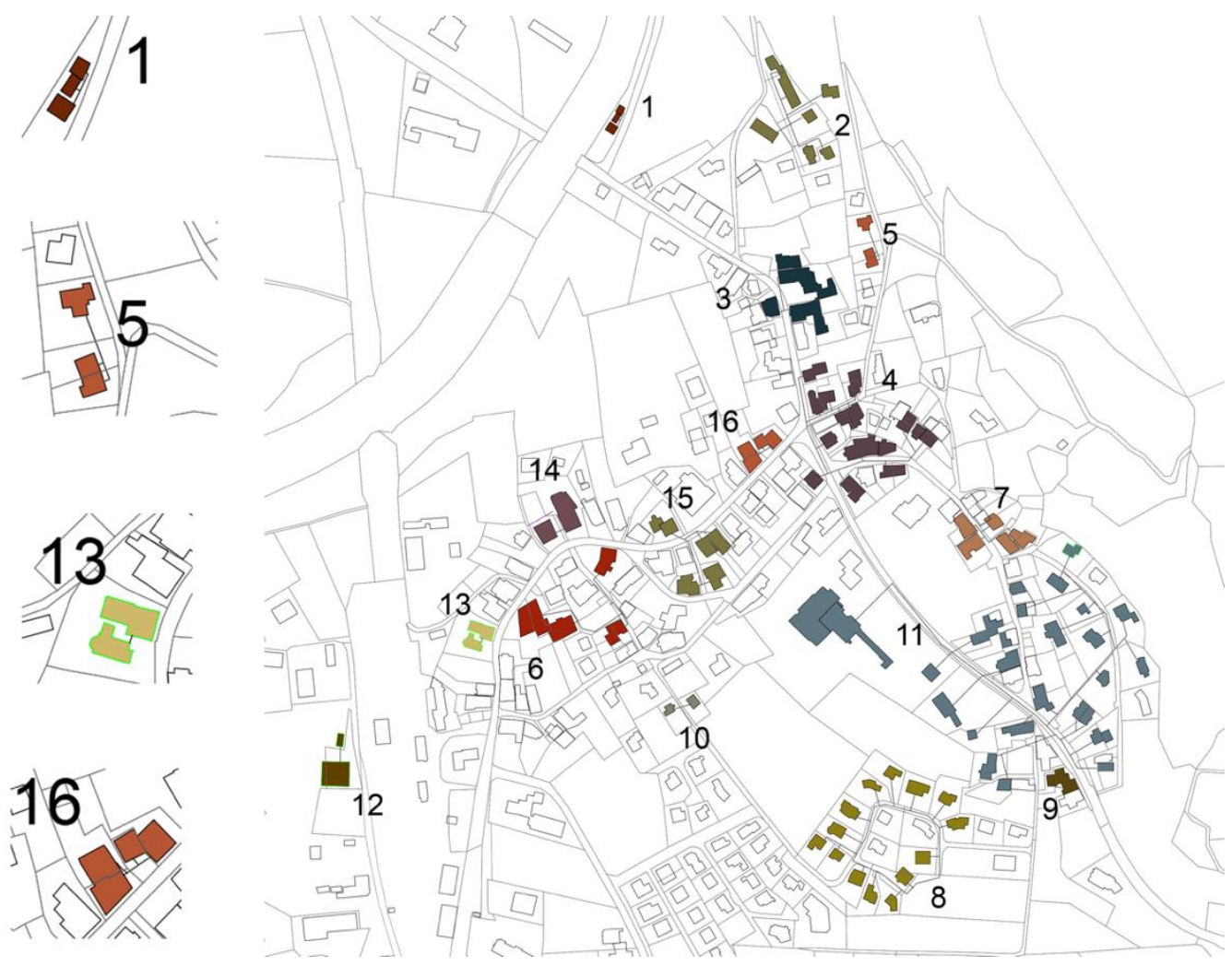

Figure 4: Microgrids identified for the building stock of the case study; selection of best performing microgrids (left)

The results show that, if connected to a microgrid, 9 out of 16 building groups would yield a cost benefit between $17.4 \%$ and $0.4 \%$ compared to the individual solution. The other groups experience higher costs when supplied using a microgrid vs. and individual solution. Table 1 and Figure 5 show 
the mechanics behind: due to the low density of the village, the length of network to connect larger amounts of buildings or buildings at farther distance results in higher distribution costs thus eliminating the benefits of economies of scale. The plot in Figure 5 shows a beneficial constellation of 3-4 buildings connected by a network at lengths between 15 and $31 \mathrm{~m}$ to yield the highest cost benefit. Additionally, the buildings in these groups have low to medium heating loads which increases the proportion of the fixed costs for heat generation over the flexible ones that are attributed to the heating loads. This makes sharing a heat generation plant advantageous. Microgrids with negative costs benefits such as No. 11 additionally feature individual buildings with large heating loads, which require the network to be larger dimensioned, thus also increasing the distribution costs. The realization of the microgrids with cost-benefits would lead to an approximate reduction of $\mathrm{CO}_{2}$ emission of $663 \mathrm{t} / \mathrm{a}$ or $30 \%$ of the total $\mathrm{CO}_{2}$ emission of the building stock.

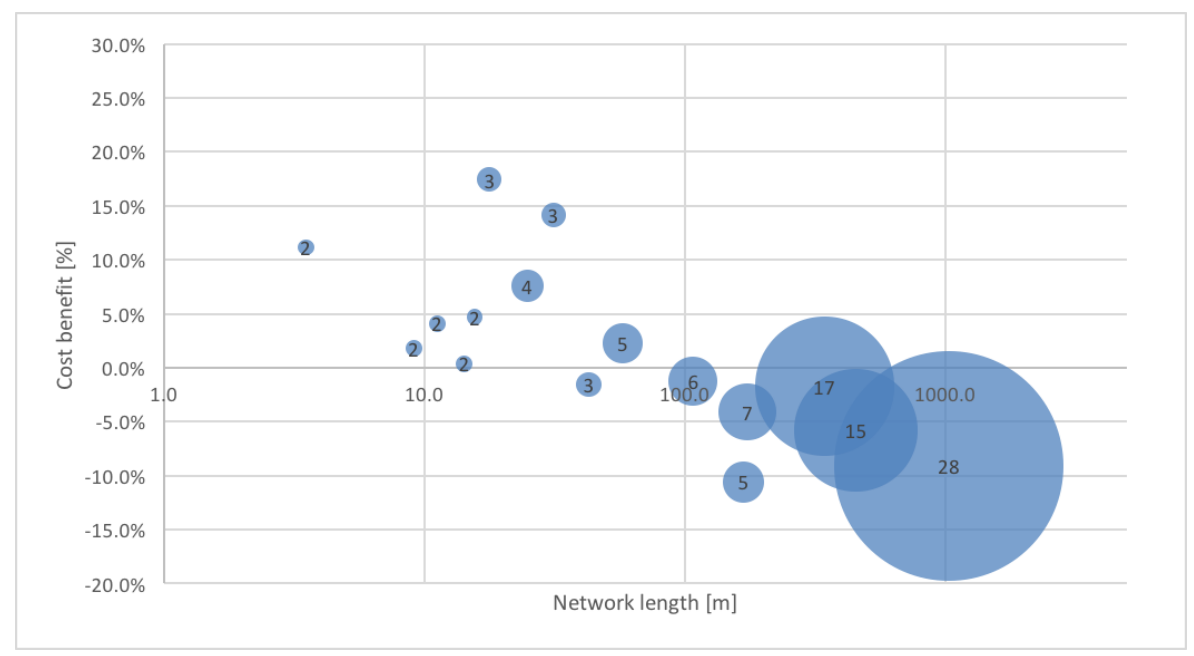

Figure 5: Cost benefit comparison of microgrids identified; bubble size indicates the number of buildings ( $\mathrm{x}$-axis uses logarithmic scale)

\subsubsection{Organization and benefits within a microgrid}

The total load of a microgrid is the aggregated load shares of its individual building members. The load shares could be used to split the investment costs for the microgrid. This would lead to varying investment costs and cost benefits for the different consumers within a microgrid. Consumers with small loads would benefit to a much higher degree than consumers with large loads. Firstly, this is due to the large portion of fixed vs. flexible costs of an individual solution and secondly, using the load share as the divider, they also contribute less to the distribution network of a microgrid solution.

This requires an internal cost balancing mechanism to make a microgrid solution equally attractive to all consumers. This can be achieved by distributing the total cost benefits also using the load shares which would results in everyone benefitting. In this case, large consumers would still have the highest share in investment, they however also achieve the highest percentage of cost benefits. This way all participants would not only be motivated to pursue a joint solution using a microgrid but also, as the total investment decreases, to pursue a retrofit in the first place. Table 2 illustrates this at the example of microgrid No.1. 


\begin{tabular}{|c|c|c|c|c|c|c|c|c|c|}
\hline & $\begin{array}{c}\text { Heating } \\
\text { power }[\mathrm{kW}]\end{array}$ & \begin{tabular}{|c|} 
Heating load \\
share / \\
consumer
\end{tabular} & $\begin{array}{c}\text { Indiv. cost MG } \\
\text { / load share } \\
{[\mathrm{CHF}]}\end{array}$ & $\begin{array}{c}\text { Indiv. Cost } \\
\text { HP+GHE [CHF] }\end{array}$ & \begin{tabular}{|c|} 
add cost MG \\
vs. $\mathrm{HP}+\mathrm{GHE}$ \\
{$[\mathrm{CHF}]$}
\end{tabular} & $\begin{array}{c}\text { cost MG vs. } \\
\text { HP + GHE [\%] } \\
\end{array}$ & \begin{tabular}{|c|} 
Indiv. cost MG \\
after \\
distribution of \\
benefits [CHF]
\end{tabular} & \begin{tabular}{|c|} 
indiv. cost \\
benefits after \\
distribution \\
[CHF]
\end{tabular} & \begin{tabular}{|c|} 
indiv. cost \\
benefits after \\
distribution \\
{$[\%]$} \\
\end{tabular} \\
\hline Building 1 & 7.3 & 0.6 & 97'134.2 & 94'294.6 & 2'839.6 & $103 \%$ & $73^{\prime} 828.8$ & - $\quad 20^{\prime} 465.8$ & $21.7 \%$ \\
\hline \begin{tabular}{|l} 
Building 2 \\
\end{tabular} & 2.1 & 0.2 & $28 ' 334.3$ & $48^{\prime} 046.6$ & 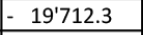 & $59 \%$ & $42^{\prime} 076.7$ & - $\quad 5 ' 969.9$ & $12.4 \%$ \\
\hline Building 3 & 2.7 & 0.2 & $36 ' 095.6$ & $53^{\prime} 263.8$ & - $17^{\prime} 168.2$ & $68 \%$ & $45^{\prime} 658.6$ & - $\quad 7 ' 605.2$ & $14.3 \%$ \\
\hline Total & 12.1 & 1.0 & $161 ' 564.1$ & $195 ' 605.0$ & - $\quad 34^{\prime} 040.9$ & $83 \%$ & $161 ' 564.1$ & - $34^{\prime} 040.9$ & $17.4 \%$ \\
\hline
\end{tabular}

Table 2: Cost benefit comparison and distribution of individual consumers for microgrid No.1 1

\section{Discussion}

In this work we present a new approach for the automated identification of building candidates for thermal microgrids using a geo-referenced building database. The resulting microgrids achieve a significant reduction in $\mathrm{CO}_{2}$ and cost benefits of up to $17.4 \%$ compared an individual heat supply using a ground heat exchanger and heat pump. These results however are highly dependent on the investment costs for both solutions. The cost data has been chosen as carefully as possible in regards to the conditions of the case study. To assess large quantities of buildings however requires simplifications and the use of averaged data that does not take local specificities into account. It might therefore be that real specific investment costs are different leading to different results in terms of cost efficiency. Also, investment costs were scaled linearly with regards to size and scale of the microgrid. For heat pumps, the cost function however is not necessarily linear as larger machines cost less per $\mathrm{kW}$ heating power. On the opposite, distribution networks with small loads can be built at a lower cost, which would result in an additional cost benefit.

Thermal microgrids have an interesting potential to contribute to the cost-efficient retrofit of the building stock given the proper selection of building members. First, as we can demonstrate on the case study, the sharing of infrastructure can have economic advantages. Reductions in investment costs allow the installation of innovative and more efficient technologies. Additionally, larger heat generation systems such as heat pumps often use more advanced components as the additional costs are marginal, thus increasing the internal efficiency. The use of advanced technologies such as ground heat exchangers, storage and high-efficiency heat pumps often results in higher investment costs than conventional technology. Using such technology in microgrids facilitates their employment in a costeffective way. As all members of a microgrids achieve an economic benefit it is more likely that a group of building owners pursues a joint investment and therefore a higher number of buildings can be retrofitted. This can be supported by suitable policies and subsidy schemes.

The identification of suitable microgrids in existing building stocks is crucial to realize such benefits. Due to the large amount of possible combinations it is not possible to examine all possible microgrid combinations manually. We have proposed a two-stage procedure for the identification and selection of possible microgrids in building stock data. At the first stage, a simplified procedure identifies suitable candidates for microgrids. This procedure translates the verbal description of closeness that is intuitive for defining a microgrid to a fuzzy logic description and combines it with other criteria based on the building's characteristics. The advantage of using a fuzzy logic with a proximity matrix in this context is its intuitive application. Defining and analyzing the proximity matrix is a quite direct approach to the 
problem, which requires no further parameter definition for solving the problem. The pair-wise combination leads to a complexity of $O\left(N^{2}\right)$. This equals the complexity of hierarchical clustering as a well-established method. There are better performing methods available for the spatial aggregation, such as k-means clustering which feature a complexity proportional to N. However, k-means clustering requires further parameter definition such as the number of clusters. This number is not known and depends on the tolerable distance between buildings and thus on the network cost parameters.

Furthermore, k-means is not able to identify convex clusters, however non-convex configurations are possible for the given problem. Finally, for the given medium size dataset, computation time for network identification compared to other activates in data preparation and post-processing was subordinate. Future research including tests with larger datasets will deliver additional data on the performance of the proposed fuzzy methods and clustering.

The estimation of the network-related investment costs requires the design of the future distribution network, which requires manual effort and is therefore time-consuming. The sum of the distances between the buildings, as acquired from the GIS data, show correlations to the length of pipe networks that are constructed for minimal lengths. For the case study this correlation is linear in two steps, for network lengths from 0 to $200 \mathrm{~m}$ and network lengths of more than $200 \mathrm{~m}$. Therefore, it seems feasible to derive the network length from the sum of the distances between the buildings in a network given enough empirical data. This derivation would allow a very quick estimation of the network costs.

The second stage is a detailed analysis and planning of microgrid candidates, which are the 16 proposed microgrids in the case study. This includes technical and economic analysis to assess feasibility and cost-benefit. The microgrids identified in stage one, featuring a limited number of buildings, are key to allow further detailed analysis and planning. This includes the detailed layout of the network geometry considering building locations, site boundaries and possible routing of pipes. These steps still require the expertise of specialized planners, which prevents this phase from being automated completely.

With the methods proposed above, not all of the microgrids identified exhibit cost-benefits. In future research, the evaluation and its criteria will need further examination, especially, to what extend they are automatable and how further criteria can be included in the identification and selection procedure in the first stage. Moreover, only single heat generation systems are currently considered. Potential further extensions of using spatial data could be considering the location of the building in respect to feasibility of using ground heat exchangers or the distance to sources of waste heat. Also, the availability of local renewable energy generation by solar thermal or photovoltaic panels could be considered using the location, geometry and direction of roof surfaces stored in the database. Thermal microgrids enable sharing and thus reducing the investment costs as well as the balancing of loads, supply and peak shaving due to joint storage. These technologies have high potential to further reduce the environmental impact of buildings, however spatial aspects are crucial. 


\section{Acknowledgements}

We thank our collaborators of the research project 'Zernez Energia 2020' for the exchange of data related to cost, energy conversion and building energy calculations. This research was partly funded by the Swiss Commission for Technology and Innovation (CTI).

\section{Author contributions}

All authors contributed to the paper, with different foci: Arno Schlueter was leading author of the background, concept and design of district heating systems and thermal microgrids, the building candidate selection criteria, the formulation of the case study and the evaluation of the results. Philipp Geyer was leading author of background and method of microgrid identification and evaluation based on fuzzy logic and clustering, building stock management and the case study evaluation. Sasha Cisar contributed to the case study setup and evaluation. All authors contributed equally to the introduction and discussion.

\section{References}

[1] Schweizer Bundesamt für Statistik (BFS), "Gebäude nach Heizungsart und Energieträger der Heizung.” [Online]. Available: http://www.bfs.admin.ch/bfs/portal/de/index/themen/09/02/blank/key/gebaeude/heizung.html. [Accessed: 03Jan-2015].

[2] U. Persson and S. Werner, "Heat distribution and the future competitiveness of district heating," Applied Energy, vol. 88, no. 3, pp. 568-576, Mar. 2011.

[3] H. Lund, S. Werner, R. Wiltshire, S. Svendsen, J. E. Thorsen, F. Hvelplund, and B. V. Mathiesen, "4th Generation District Heating (4GDH): Integrating smart thermal grids into future sustainable energy systems,” Energy, vol. 68, pp. 111, Apr. 2014.

[4] P. K. Olsen, H. Lambertsen, R. Hummelshøj, B. Bøhm, C. H. Christiansen, S. Svendsen, C. T. Larsen, and J. Worm, “A new low-temperature district heating system for low-energy buildings," in Proceedings of the 11th International Symposium on District Heating and Cooling, Iceland, 2008.

[5] A. Dalla Rosa and J. E. Christensen, "Low-energy district heating in energy-efficient building areas," Energy, vol. 36, no. 12, pp. 6890-6899, Dec. 2011.

[6] H. Lund, B. Möller, B. V. Mathiesen, and A. Dyrelund, "The role of district heating in future renewable energy systems," Energy, vol. 35, no. 3, pp. 1381-1390, 2010

[7] N. L. Truong and L. Gustavsson, "Cost and primary energy efficiency of small-scale district heating systems," Applied Energy, vol. 130, pp. 419-427, Oct. 2014.

[8] C. Reidhav and S. Werner, "Profitability of sparse district heating," Applied Energy, vol. 85, no. 9, pp. 867-877, Sep. 2008.

[9] S. Frederiksen and S. Werner, District Heating and Cooling. Studentlitteratur, 2013.

[10] J. Domínguez and J. Amador, "Geographical information systems applied in the field of renewable energy sources," Computers \& Industrial Engineering, vol. 52, no. 3, pp. 322-326, Apr. 2007.

[11] "London Heat Map."

[12] S. Nielsen and B. Möller, "GIS based analysis of future district heating potential in Denmark," Energy, vol. 57, pp. 458468, Aug. 2013.

[13] M. Shukuya and A. Hammache, Introduction to the concept of exergy: for a better understanding of low-temperatureheating and high-temperature-cooling systems. Espoo: Technical Research Centre of Finland, 2002.

[14] H. Torio and Schmidt, Dietrich, Eds., Exergy Assessment Guidebook for the Built Environment: ECBCS Annex 49 - Low Exergy Systems for High-Performance Buildings and Communities. Stuttgart: Fraunhofer Verlag, 2011.

[15] F. Meggers, V. Ritter, P. Goffin, M. Baetschmann, and H. Leibundgut, "Low exergy building systems implementation," Energy, vol. 41, no. 1, pp. 48-55, May 2012.

[16] Vetterli, Nadège and Sulzer, Matthias, "Dynamic analysis of the low-temperature district network Suurstoffi through monitoring," 2015.

[17] T. Schluck, P. Kräuchi, and Sulzer, M, "Non-linear thermal networks - How can a meshed network improve energy efficiency?," in CISBAT 2015, Lausanne, 2015, pp. 779-785.

[18] J. A. Fonseca and A. Schlueter, "Method and data analysis for assessment of local energy potentials for urban transformation: case study of a mixed use city quarter," in Proceedings of CISBAT 2013, 2013, pp. 649-654.

[19] J. Harris, Fuzzy Logic Applications in Engineering Science. Springer Science \& Business Media, 2005.

[20] S. N. Sivanandam, S. Sumathi, and S. N. Deepa, Introduction to fuzzy logic using MATLAB, vol. 1. Springer, 2007.

[21] L. Suganthi, S. Iniyan, and A. A. Samuel, "Applications of fuzzy logic in renewable energy systems - A review," Renewable and Sustainable Energy Reviews, vol. 48, pp. 585-607, Aug. 2015.

[22] C. K. Makropoulos, D. Butler, and C. Maksimovic, "Fuzzy Logic Spatial Decision Support System for Urban Water Management," Journal of Water Resources Planning and Management, vol. 129, no. 1, pp. 69-77, Jan. 2003. 
[23] U. C. Benz, P. Hofmann, G. Willhauck, I. Lingenfelder, and M. Heynen, "Multi-resolution, object-oriented fuzzy analysis of remote sensing data for GIS-ready information," ISPRS Journal of Photogrammetry and Remote Sensing, vol. 58, no. 3-4, pp. 239-258, Jan. 2004.

[24] S.-H. Lee, S.-J. Lee, and K.-I. Moon, "Smart Grid Knowledge Representation and Reasoning Based on Adaptive NeuroFuzzy Inference System,” International Journal of Software Engineering and Its Applications, vol. 8, no. 2, pp. 207-212, 2014.

[25] S. Dutta, "Qualitative spatial reasoning: A semi-quantitative approach using fuzzy logic," in Design and Implementation of Large Spatial Databases, A. P. Buchmann, O. Günther, T. R. Smith, and Y.-F. Wang, Eds. Springer Berlin Heidelberg, 1989, pp. 345-364.

[26] M.-Y. Chow and H. Tram, "Application of fuzzy logic technology for spatial load forecasting," in , 1996 IEEE Transmission and Distribution Conference, 1996. Proceedings, 1996, pp. 608-614.

[27] L.-C. Ying and M.-C. Pan, "Using adaptive network based fuzzy inference system to forecast regional electricity loads," Energy Conversion and Management, vol. 49, no. 2, pp. 205-211, Feb. 2008

[28] B. C. Arabacioglu, "Using fuzzy inference system for architectural space analysis," Applied Soft Computing, vol. 10, no. 3, pp. 926-937, Jun. 2010.

[29] R. Xu and D. C. Wunsch, Clustering. Hoboken. NJ: John Wiley \& Sons, 2009.

[30] M. Shaban, B. Urban, A. El Saadi, and M. Faisal, "Detection and mapping of water pollution variation in the Nile Delta using multivariate clustering and GIS techniques," Journal of Environmental Management, vol. 91, no. 8, pp. 17851793, Aug. 2010.

[31] T. K. Anderson, "Kernel density estimation and K-means clustering to profile road accident hotspots," Accident Analysis \& Prevention, vol. 41, no. 3, pp. 359-364, May 2009.

[32] V. M. Gómez-Muñoz and M. A. Porta-Gándara, "Local wind patterns for modeling renewable energy systems by means of cluster analysis techniques," Renewable Energy, vol. 25, no. 2, pp. 171-182, Feb. 2002.

[33] S. Fazlollahi, L. Girardin, and F. Maréchal, "Clustering Urban Areas for Optimizing the Design and the Operation of District Energy Systems,” in Computer Aided Chemical Engineering, vol. 33, Elsevier, 2014, pp. 1291-1296.

[34] G. Cartina, G. Grigoras, and E. C. Bobric, "Clustering techniques for energy losses evaluation in distribution networks," in PowerTech, 2009 IEEE Bucharest, 2009, pp. 1-5.

[35] F. Giannotti and D. Pedreschi, "Mobility, Data Mining and Privacy: A Vision of Convergence," in Mobility, Data Mining and Privacy, F. Giannotti and D. Pedreschi, Eds. Springer Berlin Heidelberg, 2008, pp. 1-11.

[36] R. Xu and I. Wunsch D., "Survey of clustering algorithms," IEEE Transactions on Neural Networks, vol. 16, no. 3, pp. 645-678, May 2005.

[37] L. G. Swan and V. I. Ugursal, "Modeling of end-use energy consumption in the residential sector: A review of modeling techniques," Renewable and Sustainable Energy Reviews, vol. 13, no. 8, pp. 1819-1835, Oct. 2009.

[38] M. Kavgic, A. Mavrogianni, D. Mumovic, A. Summerfield, Z. Stevanovic, and M. Djurovic-Petrovic, "A review of bottom-up building stock models for energy consumption in the residential sector," Building and Environment, vol. 45, no. 7, pp. 1683-1697, Jul. 2010.

[39] Institut Wohnen und Umwelt (IWU), "Typology Approach for Building Stock Energy Assessment. Main Results of the TABULA project," 2012.

[40] M. Santamouris, G. Mihalakakou, P. Patargias, N. Gaitani, K. Sfakianaki, M. Papaglastra, C. Pavlou, P. Doukas, E. Primikiri, V. Geros, M. N. Assimakopoulos, R. Mitoula, and S. Zerefos, "Using intelligent clustering techniques to classify the energy performance of school buildings," Energy and Buildings, vol. 39, no. 1, pp. 45-51, Jan. 2007.

[41] N. Gaitani, C. Lehmann, M. Santamouris, G. Mihalakakou, and P. Patargias, "Using principal component and cluster analysis in the heating evaluation of the school building sector," Applied Energy, vol. 87, no. 6, pp. 2079-2086, Jun. 2010 .

[42] P. J. Jones, S. Lannon, and J. Williams, "Modelling building energy use at urban scale," in seventh international IBPSA conference, Rio de Janeiro, Brazil, 2001, pp. 175-180.

[43] Y. Yamaguchi, Y. Shimoda, and M. Mizuno, "Proposal of a modeling approach considering urban form for evaluation of city level energy management," Energy and Buildings, vol. 39, no. 5, pp. 580-592, May 2007.

[44] “Zernez ENERGIA 2020.” [Online]. Available: http://zernezenergia2020.ch/home/. [Accessed: 02-Dec-2015].

[45] P. Geyer, A. Schlueter, and S. Cisar, "Application of Clustering for the Development of Retrofit Strategies for large Building Stocks," Advanced Engineering Informatics, submitted 2015.

[46] “EnDK: Gebäudeenergieausweis der Kantone (GEAK).” [Online]. Available: https://www.geak.ch. [Accessed: 22-Mar2015].

[47] P. Geyer, A. Schlueter, and S. Cisar, "A Performance-Based Clustering Model for Retrofit Management of Building Stocks," in The 21 st International Workshop on Intelligent Computing in Engineering, Cardiff, UK, 2014

[48] Energie Schweiz, "Ermittlung der Heizleistung." [Online]. Available: http://www.bfe.admin.ch/php/modules/publikationen/stream.php?extlang=de\&name=de_419227968.pdf. [Accessed: 11 Nov-2015].

[49] “ecoinvent.” [Online]. Available: http://www.ecoinvent.org/. [Accessed: 12-Apr-2014]. 


\section{Appendix}

Table 1: Conversion factors and efficiencies for different energy sources and heating systems [49].

\begin{tabular}{lll} 
Type of Heating System & $\begin{array}{c}\text { Emissions } \\
\text { kg CO } \mathbf{~ e q . ~} \\
\text { per kWh }\end{array}$ \\
\hline Conversion factor oil & 0,290 & 0,85 \\
\hline Conversion factor electricity & 0,459 & 0,90 \\
\hline Conversion factor DH & 0,045 & 0,90 \\
\hline Conversion factor wood & 0,017 & 0,80 \\
\hline Conversion factor wood chips & 0,022 & 0,80 \\
\hline Conversion factor heat pump (air/water) & 0,061 & 3,50 \\
\hline Conversion factor heat pump (water/water) & 0,066 & 4,00 \\
\hline Conversion factor heat pump (soil/water) & 0,066 & 4,00 \\
\hline Conversion factor District Heating & 0,045 & 0,90
\end{tabular}




\section{Author CV's}

\section{Arno Schlueter (corresponding author)}

Arno Schlueter holds a degree in Architecture (Dipl.Ing.) from the Technical University of Karlsruhe, a postgraduate degree in building informatics and a $\mathrm{PhD}$ in building systems from ETH Zürich. In 2010 he was appointed Assistant Professor and in 2014 Full Professor of Architecture and Building Systems (A/S) at the Institute of Technology in Architecture (ITA), ETH Zurich. Since 2013 he is also Principal Investigator at the Singapore-ETH Future Cities Lab (FCL). In his research he focuses on sustainable building and urban systems, new adaptive components and their synergetic integration into architecture and urban design using computational approaches for modelling, analysis and control. He co-founded the design and engineering office Keoto, where he is part of the management board. His work has been published in scientific journals, magazines and book and has won international competitions and prizes.

\section{Philipp Geyer}

Philipp Geyer is assistant professor at the Department of Architecture within the Faculty of Engineering Science of the KU Leuven. His research field is sustainable building design, construction and technology supported by intelligent computation, modelling, and simulation. He holds a Diploma and a Doctor of Engineering in architecture $(\mathrm{PhD})$ from Technical University of Berlin. In his doctoral research, which he partly conducted as visiting scientist at Massachusetts Institute of Technology (MIT), he developed a method for applying Multidisciplinary Design Optimization (MDO) to building design. This approach adapted methods from aerospace engineering and developed them further for supporting decision making in performance-oriented building design. As a postdoc fellow at Technische Universität München (TUM) and Swiss Federal Institute of Technology Zurich (ETH) conducted research on performance-oriented and strategic design by systems engineering and developed the method of parametric systems modelling (PSM) for the built environment. He is committee member of the European Group for Intelligent Computing in Engineering (eg-ice) has more than 40 publications in international journals, books and proceedings and coedited three scientific peerreviewed publications. Furthermore, he is responsible for system design, optimization, and construction in the research enterprise Watergy. This enterprise develops innovative energy and water systems for sustainable buildings and greenhouses, which provide air moistening and dehumidification, heating, cooling and water regeneration.

\section{Sasha Cisar}

Sasha Cisar is an architect and currently a doctoral researcher at the Chair of Sustainable Construction, ETH Zürich. His research focuses on the assessment of environmental impact of energy related aspects in urban planning. Between 2013 and 2015 he was a researcher at the Chair of Architecture and Building Systems, ETH Zürich amongst other contributing to the CTI research project Zernez Energia 
2020. Between 2011 and 2013 he was working as an architect in an architectural practice in Zürich focusing on sustainable design and buildings. He has contributed to a number of papers and lectured accordingly. Sasha Cisar holds a BSc and MSc in architecture. 